Fayçal Dergal ${ }^{1,2 *}$, Djahida Lerari ${ }^{1}$, Khaldoun Bachari ${ }^{1}$

${ }^{1}$ Centre de Recherche Scientifique et Technique en Analyses Physico-chimiques (CRAPC), Bp 384 Bousmail Tipaza, Algeria

${ }^{2}$ University of Tlemcen, Laboratoire de Catalyse et Synthèse en Chimie Organique (LCSCO) Department of Chemistry, Tlemcen, 13000, Algeria

*dergal.faycal@crapc.dz

\title{
PLASTICIZING PROPERTIES IMPROVEMENT OF POLY (4-VINYLPYRIDINE)/CLAY COMPOSITES: EFFECT OF COMPOSITION AND CLAY NATURE
}

\begin{abstract}
A significant number of investigations have been reported on the elaboration and characterization of Polymer/Clays composites, via different methods. In our work, new composites materials were successfully prepared by in-situ polymerization of 4-vinylpyridine (4VP), in presence of two different types of Algerian modified clays (Maghnia and Mostaganem), noted (BC) and (MC), respectively. Different percentage clays $(1 \mathrm{wt} \%, 3 \mathrm{wt} \%$ and $5 \mathrm{wt} \%)$ have been used. The differential scanning calorimetry analysis reveals the variation of glass transition temperature ( $\mathrm{Tg}$ ) of the copolymer in the composite materials. We show a decrease glass transition temperature (Tg) from $147^{\circ} \mathrm{C}$ to $131^{\circ} \mathrm{C}$ for P4VP-BC and from $147^{\circ} \mathrm{C}$ to $124^{\circ} \mathrm{C}$ for P4VP-MC according to the increase percentage of clays. Thermogravimetric analysis (TGA) shows good stability of composite materials at high temperature. Fourier Transformed Infrared (FTIR), Scanning Electron Microscopy coupled with Energy dispersive X-Ray Spectroscopy (SEM-EDX) and ${ }^{1} \mathrm{H}$ NMR spectroscopy are used to show the presence of the clays in the materials.
\end{abstract}

Keywords: Composite; P4VP; clays; in-situ polymerization

\section{INTRODUCTION}

Poly(4-vinylpyridine) (s) are an important class of polymers, exhibiting interesting properties due to the presence of basic nitrogen atom in the pyridine ring [1]. Nitrogen atom enables a variety of reactions on the vinyl pyridine polymer such as reactions with acids, quaternization, and complexation of metals. Poly(4-vinylpyridine) is particularly useful in applications as polyelectrolytes and polymeric reagents, and in other electrical fields applications. Poly(4-vinylpyridine) is neutral at $\mathrm{pH} 7$ and hence insoluble in pure water. In the presence of protons (in acidic medium), it becomes charged and water-soluble. The potentiometric (sensitivity with respect to protons), viscosity, associative, and conformational behaviors are well known [2,3]. The bentonite is the most smectite clay commonly used due to its high permeability, high surface area, swelling behavior, adsorption, and high cation exchange capacity (CEC) [4]. Mt is used in various applications such as hydrogeology, civil 
engineering, petroleum engineering, environmental sciences and biological applications and catalysis [5]. This clay is 2:1 type of alumino-silicate with a crystalline structure presenting an alumina octahedral sandwiched between two tetrahedral layers of silica $[5,6]$. Because of the isomorphous substitution of $\mathrm{Al} 3$ ? for $\mathrm{Si} 4$ ? in the tetrahedral layer and $\mathrm{Mg}$ for $\mathrm{Al}$ in the octahedral layer, the negative surface charge on the clay is compensated by exchangeable cations $\mathrm{Na}, \mathrm{Ca}, \mathrm{K}$...etc. [5]. The intercalation of exchangeable cations in the layers space with different organic molecules, particularly soluble polymers, yields the so-called polymer-clay nanocomposites.

These materials exhibit a very remarkably enhanced mechanical and barrier properties combined with a good thermal and chemical stability [5-8]. Bentonite clays are largely used in many industrial products such as ceramics, paintings, coatings, drilling mud, etc... The adsorption of the macromolecules on the surface of these materials modifies their properties, particularly the rheological ones, as well as the stability of the argillaceous suspensions [9-11]. All this are of great technological interest, since the based clay suspensions are good adsorbents for the retention of the polymer waste from solutions. They are also less expensive than the usual adsorbents such as activated carbon. Thus, they were the topic of a great number of studies, particularly when used for dyes retention [4], One of the most widely used adsorbents is activated carbon due to its high adsorption capacity for organic matter; however, it is expensive and difficult to regenerate. From this point of view, many nonconventional low-cost adsorbents have been proposed and developed for dye removal, e.g., bentonite [13]. Various synthetic materials are attractive adsorbents, such as poly(4-vinylpyridine) [14-16]. Clay minerals and poly(4-vinylpyridine) have high adsorption capability for various kinds of dyestuffs. The poly(4-vinylpyridine)/Clay's system has been studied in some other works as a mixture of clays and P4VP polymer [17-18].

In the present study, Bentonite Clays (BC) and Mostaganem Clays (MC) were dispersed in polymer matrix by in-situ radical polymerization of 4-vinylpyridine monomer [19-21]. The obtained P4VP/clays composites at different percentages of inorganic component have a better organophilic character [2].

The composites were characterized by using Thermogravimetric Analysis (TGA), Differential Scanning Calorimetry (DSC), Fourier transform infrared analysis (FTIR), Scanning Electron Microscopy coupled with Energy dispersive X-Ray Spectroscopy (SEMEDX) and ${ }^{1} \mathrm{H}$ NMR spectroscopy.

\section{EXPERIMENTAL PROCEDURE}

\section{Materials}

4-vinylpyridine (4VP) was distilled under reduced pressure. Potassium persulfate (KPS) as free-radical initiator was used without further purification. Clays from Maghnia and Mostaganem noted $\mathrm{BC}$ and $\mathrm{MC}$ respectively were kindly supplied by ENOF (Entreprise Nationale des Produits Miniers non-ferreux et des Substances Utiles) (Algeria). Their chemical compositions were represented in Tables 1 and 2 respectively. These clays were organically modified by Alkyl ammonium cations.

Table 1. Chemical composition of Bentonite clay (BC)

\begin{tabular}{cccccccccc}
\hline Component & $\mathrm{SiO}_{2}$ & $\mathrm{Al}_{2} \mathrm{O}_{3}$ & $\mathrm{Fe}_{2} \mathrm{O}_{3}$ & $\mathrm{CaO}$ & $\mathrm{MgO}$ & $\mathrm{Na}_{2} \mathrm{O}$ & $\mathrm{K}_{2} \mathrm{O}$ & $\mathrm{TiO}_{2}$ & LOI \\
\hline $\begin{array}{c}\text { Content } \\
\text { (wt. \%) }\end{array}$ & 65.2 & 17.25 & 2.10 & 1.20 & 3.10 & 2.15 & 0.60 & 0.20 & 8.20 \\
\hline
\end{tabular}


Table 2. Chemical composition of Mostaganem Clay (MC)

\begin{tabular}{ccccccccccccccc}
\hline component & $\mathrm{SiO}_{2}$ & $\mathrm{TiO}_{2}$ & $\mathrm{Al}_{2} \mathrm{O}_{3}$ & $\mathrm{Fe}_{2} \mathrm{O}_{3}$ & $\mathrm{FeO}$ & $\mathrm{MnO}$ & $\mathrm{MgO}$ & $\mathrm{CaO}$ & $\mathrm{Na}_{2} \mathrm{O}$ & $\mathrm{K}_{2} \mathrm{O}$ & $\mathrm{H}_{2} \mathrm{O}^{+}$ & $\mathrm{H}_{2} \mathrm{O}^{-}$ & $\mathrm{SO}_{3}$ & $\mathrm{P}_{2} \mathrm{O}_{5}$ \\
\hline $\begin{array}{c}\text { Content } \\
\text { (wt. \%) }\end{array}$ & 65.50 & 0.27 & 13.85 & 2.91 & 0.70 & 0.03 & 2.27 & 1.86 & 2.22 & 0.97 & 3.27 & 6.06 & 0.02 & 0.06 \\
& & & & & & & & & & & & & &
\end{tabular}

Synthesis of Poly(4-vinylpyridine)/clays composites

Clays (BC and MC) were first dispersed as suspension as different ratios $(0.05 \mathrm{~g}$ from $1 \mathrm{wt} \%, 0.15 \mathrm{~g}$ from $3 \mathrm{wt} \%$ and $0.25 \mathrm{~g}$ from $5 \mathrm{wt} \%$ ) in $10 \mathrm{ml}$ of ethanol and stirred for $24 \mathrm{~h}$. At the same time, $0.1 \mathrm{~g}$ of Potassium Persulfate (KPS) was suspended in $5 \mathrm{ml}$ bi-distilled water, by stirring for $4 \mathrm{~h}$ at ambient temperature. In second step, the two solutions were mixed and stirred for $24 \mathrm{~h}$ at $0^{\circ} \mathrm{C}$. Finally, $5 \mathrm{~g}$ of 4 -vinylpyridine were added and the solution was purged with nitrogen gas for $20 \mathrm{~min}$. The samples were polymerized in an oil bath at $65^{\circ} \mathrm{C}$ for $168 \mathrm{~h}$ to obtain poly(4-vinylpyridine)/Clays with (1 wt $\%, 3 \mathrm{wt} \%$ and $5 \mathrm{wt} \%)$. The composite materials were obtained by precipitation of polymer solution in diethyl ether.

\section{Characterization}

The FTIR analysis of KBr pellets forms are performed using the apparatus Magna IR 560 spectrometer Nicolet. ESEM-EDX analyses are conducted using the apparatus MINI-SEM TM-1000 HITACHI.

${ }^{1} \mathrm{H}$ NMR of pure P4VP and composite materials are performed on a Brucker advanced spectrometer operating at $400 \mathrm{MHz}$ in $\mathrm{CDCl}_{3}$ at $25^{\circ} \mathrm{C}$, using tetramethylsilane (TMS) as the internal reference standard.

Thermal stability of composite materials P4VP-clays have been studied in the temperature range between $20^{\circ} \mathrm{C}$ and $800^{\circ} \mathrm{C}$ under air by thermogravimetric analysis performed using the TA instrument "TGA Q50" apparatus.

The glass transition temperature $(\mathrm{Tg})$ of the poly(4-vinylpyridine) and of clays composites were determined by Differential Scanning Calorimetry (DSC) using TA instrument "DSC Q100" apparatus under nitrogen at $10^{\circ} \mathrm{C} / \mathrm{min}$ the temperature lying between $10^{\circ} \mathrm{C}$ and $180^{\circ} \mathrm{C}$. The $\mathrm{Tg}$ values were determined at the midpoint of the second scan.

\section{RESULTS AND DISCUSSION}

\section{Fourier transform infrared (FTIR) and Nuclear Magnetic Resonance $\left({ }^{1} \mathrm{H}-\mathrm{NMR}\right)$ spectroscopies}

These composite materials were characterized using FTIR technique. The general spectra are represented in figure 1 and 2.

In the FTIR spectrum of P4VP-Clays, containing 1\%, 3\% and 5\% of Bentonite (BC) and Mostaganem clays (MC) respectively (figure 1 and 2 ).

The presence of P4VP is attested by a slight peak at $1600 \mathrm{~cm}^{-1}$ corresponding to a stretching vibration of $\mathrm{C}=\mathrm{C}$. It is correlated with a peak at $1420 \mathrm{~cm}^{-1}$ attributed to the stretching vibration of $\mathrm{C}=\mathrm{N}$ in the aromatic ring (Figure 1 and 2). Unmodified Bentonite and 
Mostaganem Clays are represented. The presence of P4VP is clearly attested by two narrow bands at $1600 \mathrm{~cm}^{-1}$ and $1420 \mathrm{~cm}^{-1}$ respectively.
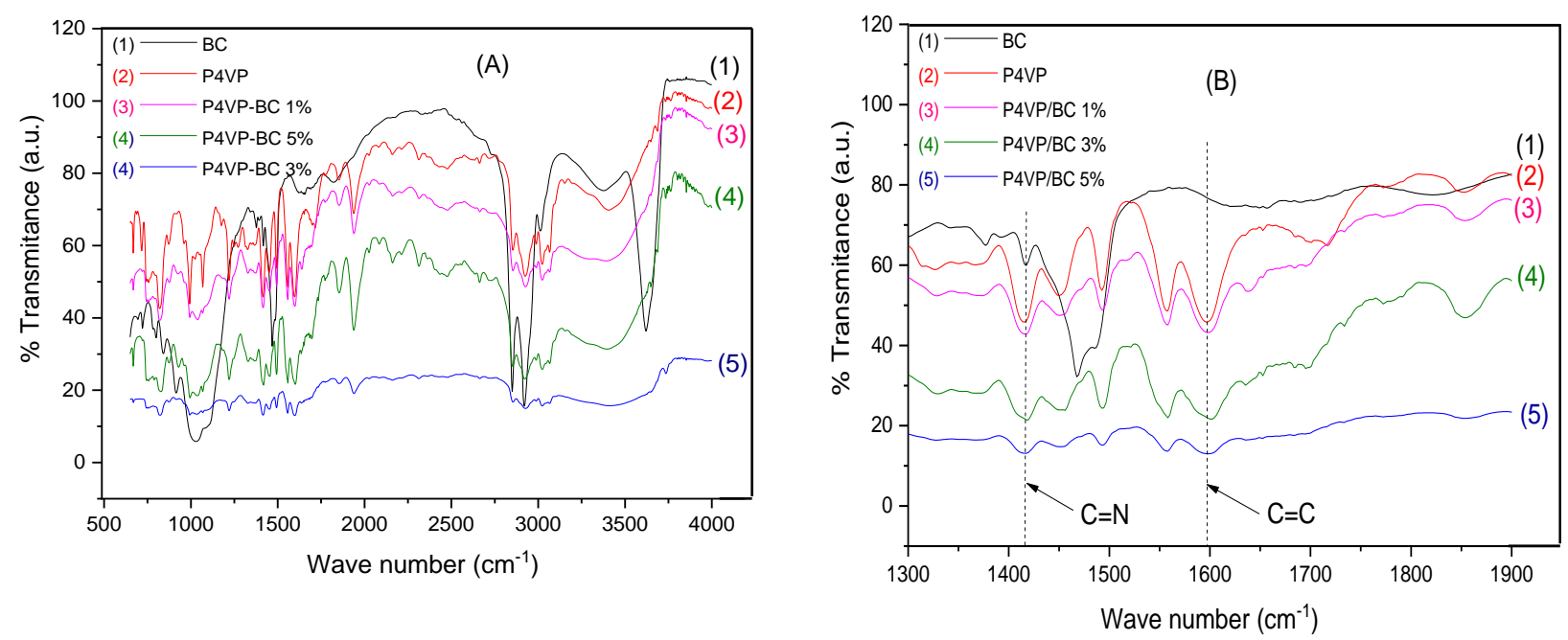

Fig. 1. FTIR spectra (A) and Magnification (B) of (1) BC, (2) P4VP, (3) P4VP-BC 1\%, (4) $P 4 V P-B C 3 \%$, (5) P4VP-BC 5\%
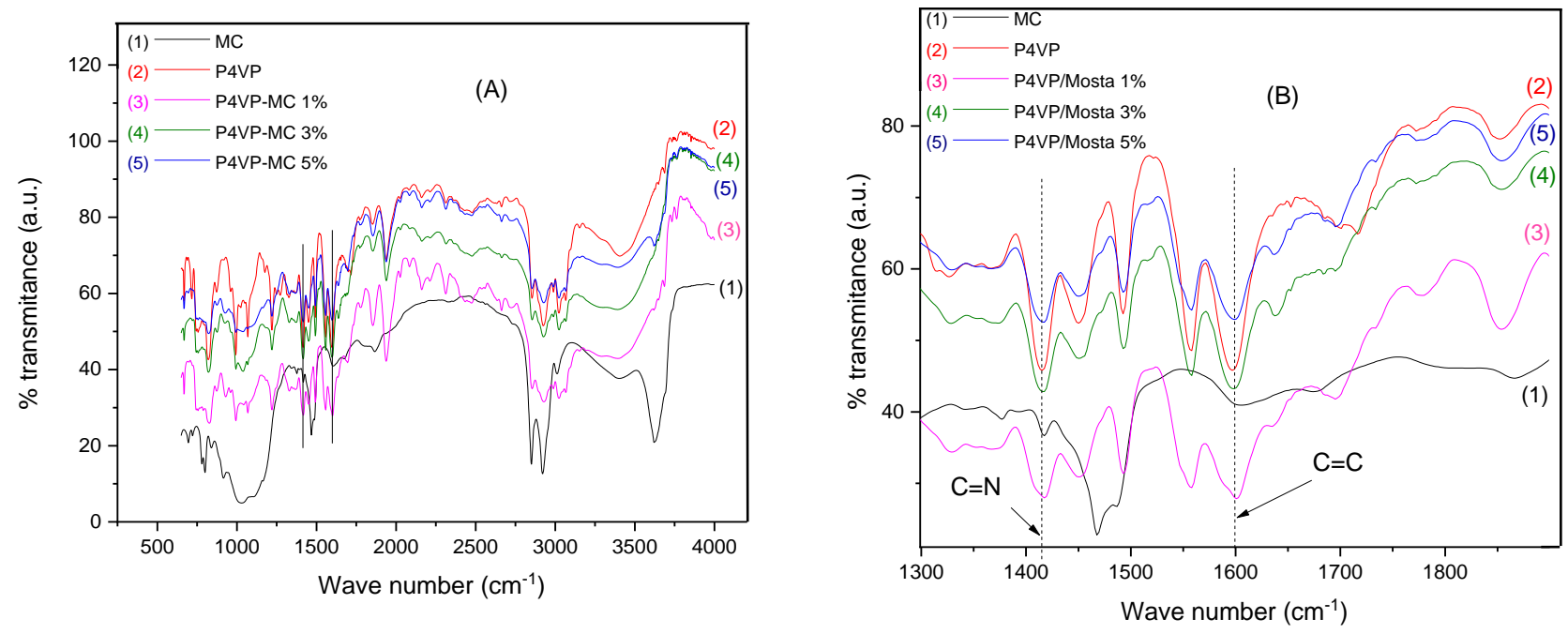

Fig. 2. FTIR spectra (A) and Magnification (B) of (1) MC, (2) P4VP, (3) P4VP-MC 1\%, (4) P4VP-MC 3\%, (5) P4VP-MC 5\%

The ${ }^{1} \mathrm{H}$ NMR analysis was carried out to complete the FTIR characterizations. As shown in Figures 3 and 4 [19], the characteristic signals of the poly(4-vinylpyridine) P4VP, $\delta=1.5 \mathrm{ppm}$ for the $\mathrm{CH}_{2} \mathrm{CH}, \delta=6.5 \mathrm{ppm}$ and $\delta=8.2-8.5 \mathrm{ppm}$ of ${ }^{1} \mathrm{H}$ proton were observed. All these values are consistent with those described by Yong et al. [24]. The comparison of the ${ }^{1} \mathrm{H}-\mathrm{NMR}$ spectra of pure P4VP, P4VP-BC, P4VP-MC (Figure 3 and 4) reveals that P4VP is well coated onto clays without significant modification.

\section{Thermogravimetric analysis TGA}

The effect of clay dispersion on the P4VP thermal stability was evaluated by thermogravimetric analysis. As shown in the figures 5 and 6, the thermo- degradation process of P4VP/Clays composites are not different from the pure P4VP. However, we observe a little 
decrease in the degradation temperature by increasing clays percentage. The weight loss of the P4VP is due to the fast dequaternisation phenomenon resulting from the scission of $\mathrm{C}-\mathrm{N}^{+}$ bonds. Claret and al. showed that near $300{ }^{\circ} \mathrm{C}$, the fundamental stage of degradation consists in an electron transfer from the halogen $\mathrm{X}^{-}$to the $\pi^{*}$ orbital of the aromatic ring. A complex with charge transfer is formed with simultaneous homolytic scission of $\mathrm{C}_{-} \mathrm{N}^{+}$bond [22].

Table 3 shows the thermal characteristics of different composites materials compared with P4VP, Bentonite Clay and Mostaganem Clay. We observe a stability of the degradation at $50 \%$ of weight loss of different composite materials if we compared with the values of P4VP. The Clay and the ratio between P4VP and Clay do not influence the degradation.

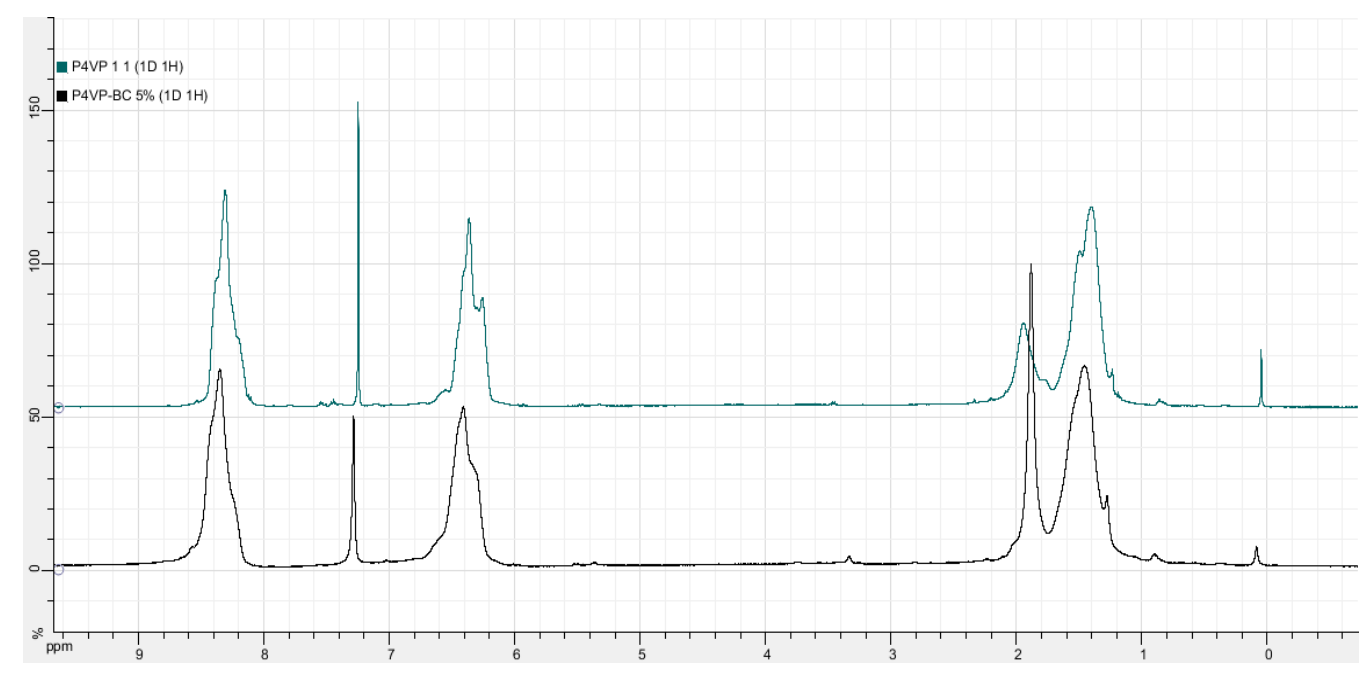

Fig. 3. ${ }^{1} \mathrm{H}-\mathrm{NMR}$ CPMAS Spectra of: P4VP, P4VP-BC 5\%

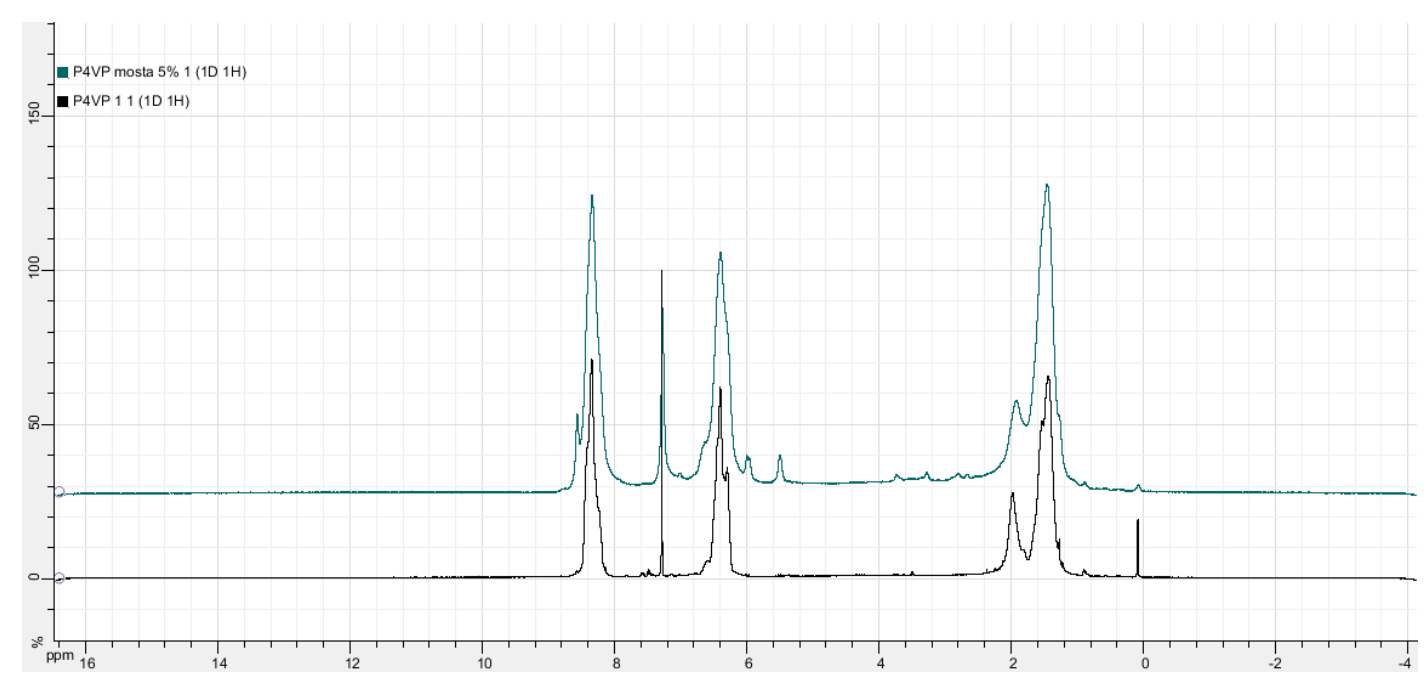

Fig. 4. ${ }^{1} \mathrm{H}$ NMR CPMAS Spectra of: P4VP, P4VP-MC 5\% 
Table 3. Thermal Characteristics of different composite materials

\begin{tabular}{cccccc}
\hline & $\mathrm{T}_{\mathrm{d}}\left({ }^{\circ} \mathrm{C}\right)$ & $\mathrm{T}_{10}\left({ }^{\circ} \mathrm{C}\right)$ & $\mathrm{T}_{50}\left({ }^{\circ} \mathrm{C}\right)$ & $\mathrm{Sdr}$ & $\mathrm{R}_{500}(\%)$ \\
\hline Bentonite Clay (BC) & 53 & 225 & - & 200 & 74 \\
P4VP & 50 & 347 & 380 & 270 & 7.8 \\
P4VP-BC 1\% & 60 & 310 & 375 & 270 & 12.1 \\
P4VP-BC 3\% & 53 & 275 & 373 & 275 & 12.5 \\
P4VP-BC 5\% & 45 & 300 & 372 & 276 & 12.3 \\
Mostaganem Clay (MC) & 30 & 275 & - & 150 & 80.4 \\
P4VP-MC 1\% & 70 & 280 & 375 & 269 & 10.9 \\
P4VP-MC 3\% & 48 & 210 & 377 & 273 & 10.42 \\
P4VP-MC 5\% & 50 & 300 & 375 & 250 & 17.4 \\
\hline
\end{tabular}

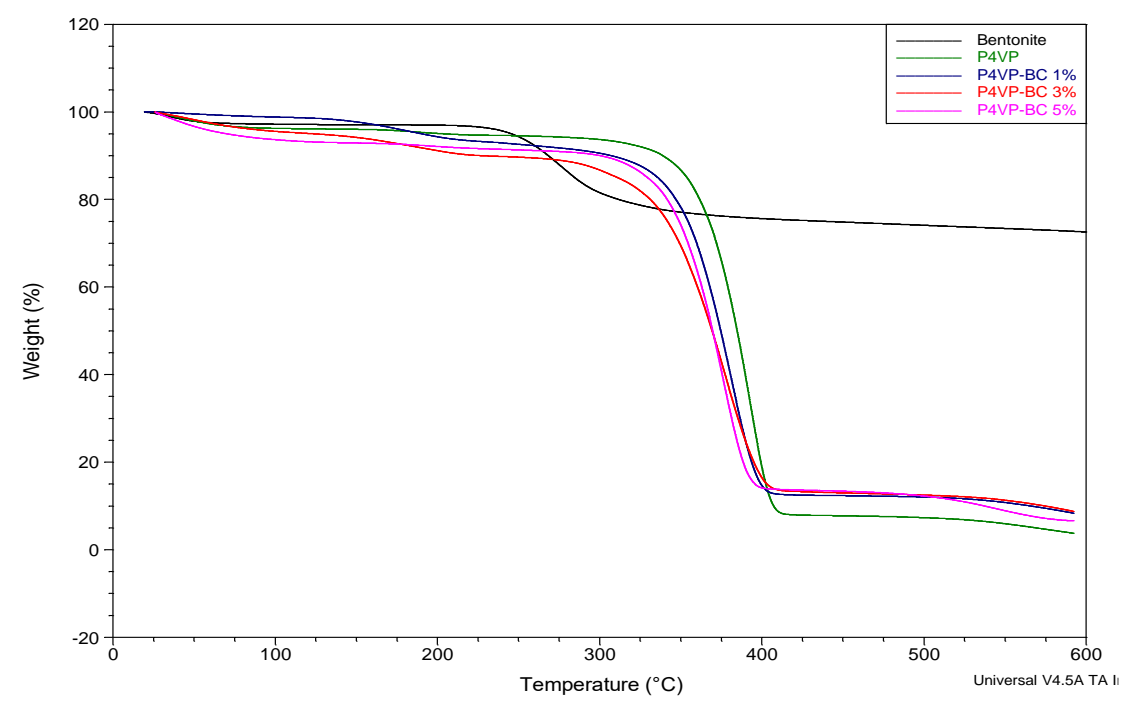

Fig. 5. TGA thermograms of: P4VP, Bentonite clay (BC), P4VP-BC 1\%, P4VP-BC 3\% and $\mathrm{P} 4 \mathrm{VP}-\mathrm{BC} 5 \%$ under nitrogen at $10^{\circ} \mathrm{C} / \mathrm{min}$

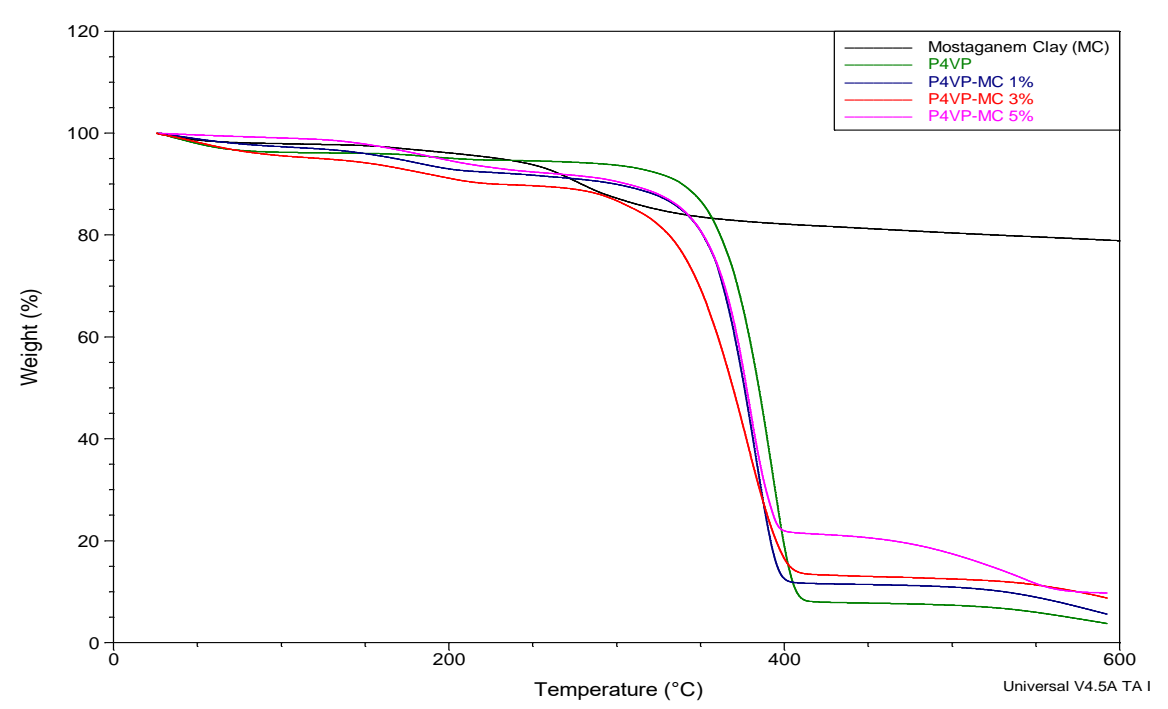

Fig. 6. TGA thermograms of: P4VP, Mostaganem clay (MC), P4VP-MC 1\%, P4VP-MC 3\% and P4VP-MC $5 \%$ under nitrogen at $10^{\circ} \mathrm{C} / \mathrm{min}$ 


\section{Differential scanning calorimetry analysis DSC}

Figures 7 and 8 display DSC thermograms of pure poly(4-vinylpyridine) and their corresponding composites poly(4-vinylpyridine)/Clays prepared with different percentages of Bentonite and Mostaganem organically modified clays. The glass transition temperatures of the composite materials (at the middle point) decrease if compared with the Tg of the P4VP under the same conditions. The Tg decreases as a function of the plasticization phenomenon appearance [25]. Moreover, this diminution increases with the percentage of Clays and it is more important for the composites prepared with the MC clay (Table 4). This phenomenon is due to the dispersion of the clay particles in the polymer Matrix, and it informs us that the polymer was not sandwiched between the clay layers. So, we have rather an encapsulation phenomenon and the polymer covered completely the clay particles, as confirmed by SEM-EDX analysis.

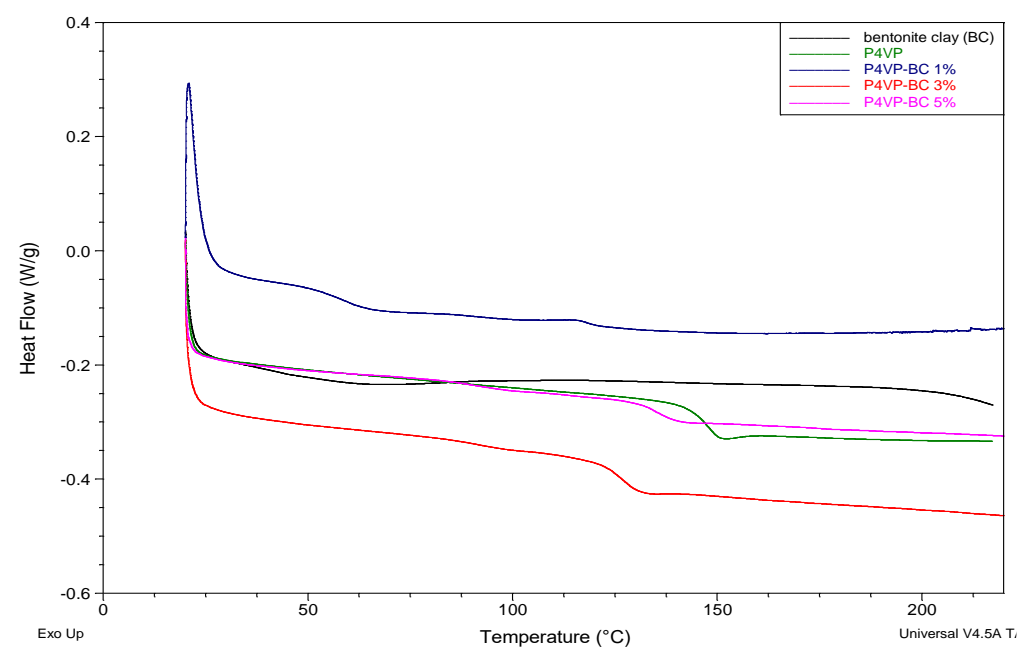

Fig. 7. DSC Thermograms of P4VP, Bentonite clay (BC), P4VP-BC 1\%, P4VP-BC $3 \%$ and P4VP-BC $5 \%$ under nitrogen atmosphere at $10^{\circ} \mathrm{C} / \mathrm{min}$

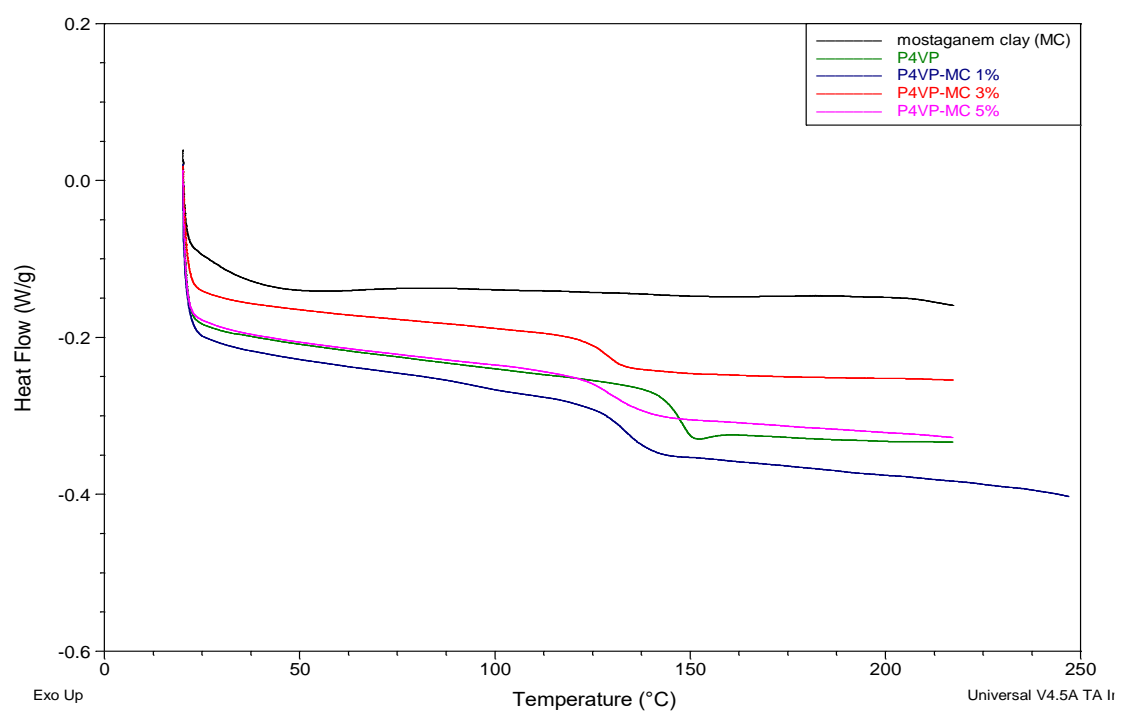

Fig. 8. DSC thermograms of: P4VP, Mostaganem clay (BC), P4VP-MC 1\%, P4VP-MC 3\% and P4VP-MC $5 \%$ under nitrogen atmosphere at $10^{\circ} \mathrm{C} / \mathrm{min}$ 
Table 4. The glass transition temperature of different composite materials

\begin{tabular}{ccccc}
\hline & P4VP & P4VP-BC 1\% & P4VP-BC 3\% & P4VP-BC 5\% \\
\hline $\operatorname{Tg}\left({ }^{\circ} \mathrm{C}\right)$ & 147 & 140.4 & 132.5 & 131.5 \\
\hline & & & \\
\hline $\operatorname{Tg}\left({ }^{\circ} \mathrm{C}\right)$ & P4VP & P4VP-MC 1\% & P4VP-MC 3\% & P4VP- MC 5\% \\
\hline
\end{tabular}

Scanning Electron Microscopy coupled with Energy Dispersive X-Ray Spectroscopy (SEMEDX) analysis

Electron Microscopy coupled with Energy Dispersive X-Ray Spectroscopy (SEM-EDX) characterizations was performed. The SEM-EDX results of the raw clays show that Aluminum and silica are present with the largest percentages. The presence of Aluminum (Al) and silica ( $\mathbf{S i}$ ) are present for all the composites P4VP-Clays with different percentages (Figures 9 to 14).

The Energy Dispersive X-Ray Spectroscopy (EDX) allows us to observe that the different ratio between the $\mathrm{Si}$ and $\mathrm{Al}$ are not changed for all of composite's materials (Table 5). In the other hand, the scanning electron microscopy shows the presence of the silica Si and aluminum $\mathrm{Al}$, in all materials.

These observations confirm the IRTF results. The polymer was not sandwiched between the layers of clay and we have rather an encapsulation phenomenon. We have completely covered the clay particles by the polymer.

Table 5. Si/Al Ratios different composite materials

\begin{tabular}{ccccc}
\hline & Bentonite Clay (BC) & P4VP-BC 1\% & P4VP-BC 3\% & P4VP-BC 5\% \\
\hline Ratio (Si/Al) & 3.80 & 3.76 & 3.77 & 3.83 \\
\hline & Mostaganem Clay (MC) & P4VP-MC 1\% & P4VP-MC 3\% & P4VP-MC 5\% \\
\hline Ratio (Si/Al) & 4.70 & 4.62 & 4.73 & 4.68 \\
\hline
\end{tabular}

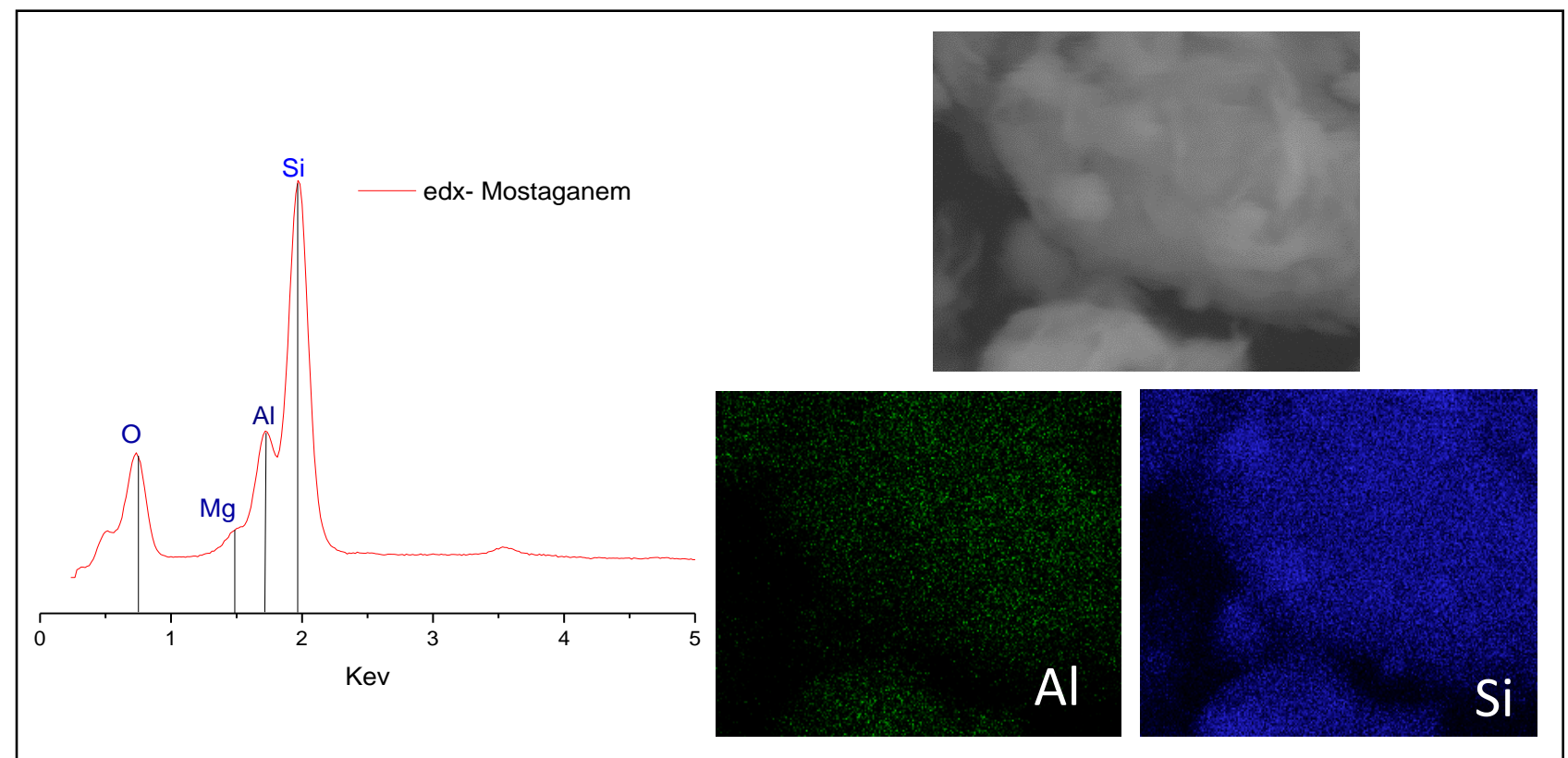

Fig. 9. ESEM observations (scale bare $=10 \mu \mathrm{m}$ ), EDX spectrum and cartography of Mostaganem clay (MC) 


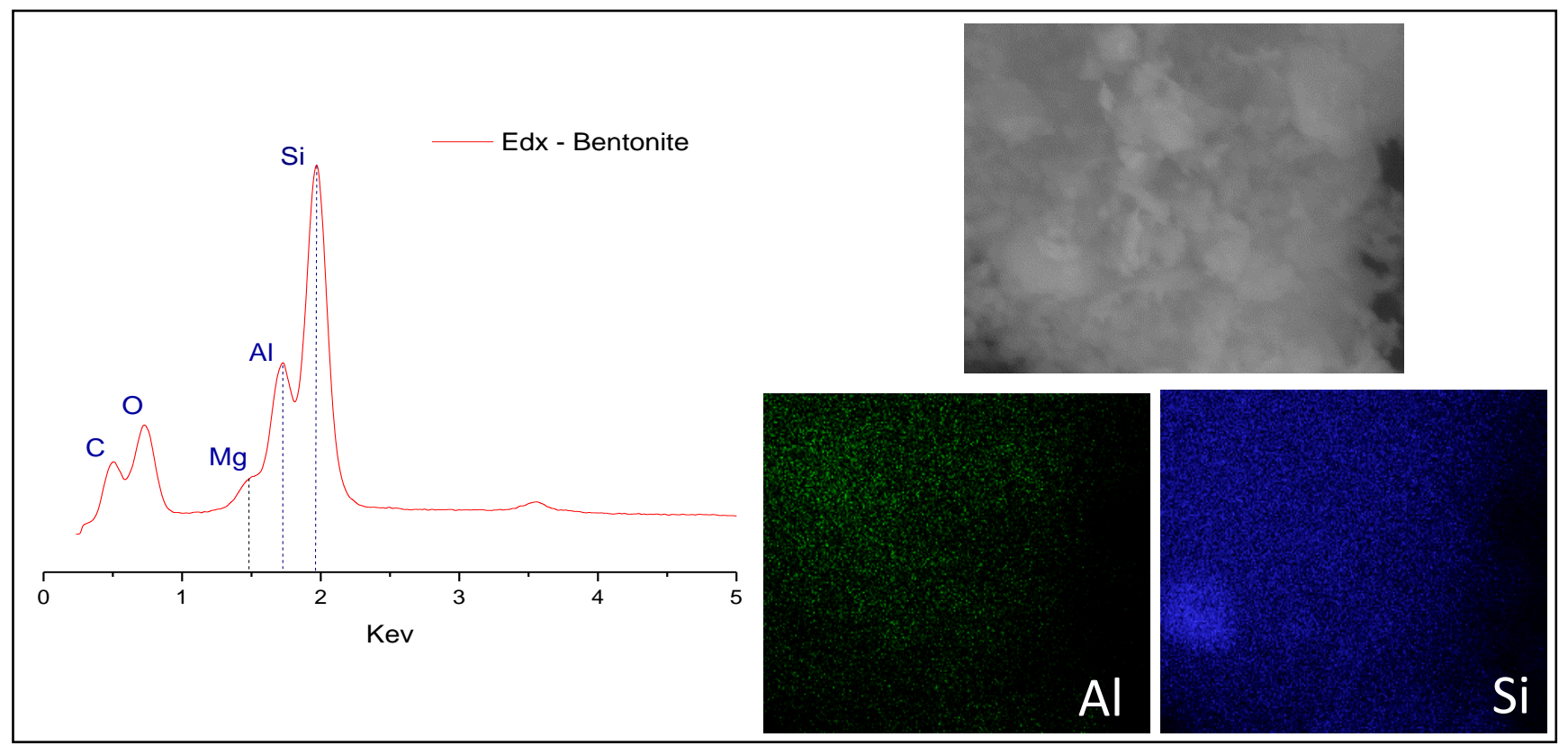

Fig. 10. ESEM observations (scale bare $=10 \mu \mathrm{m}$ ), EDX spectrum and cartography of Bentonite clay $(B C)$
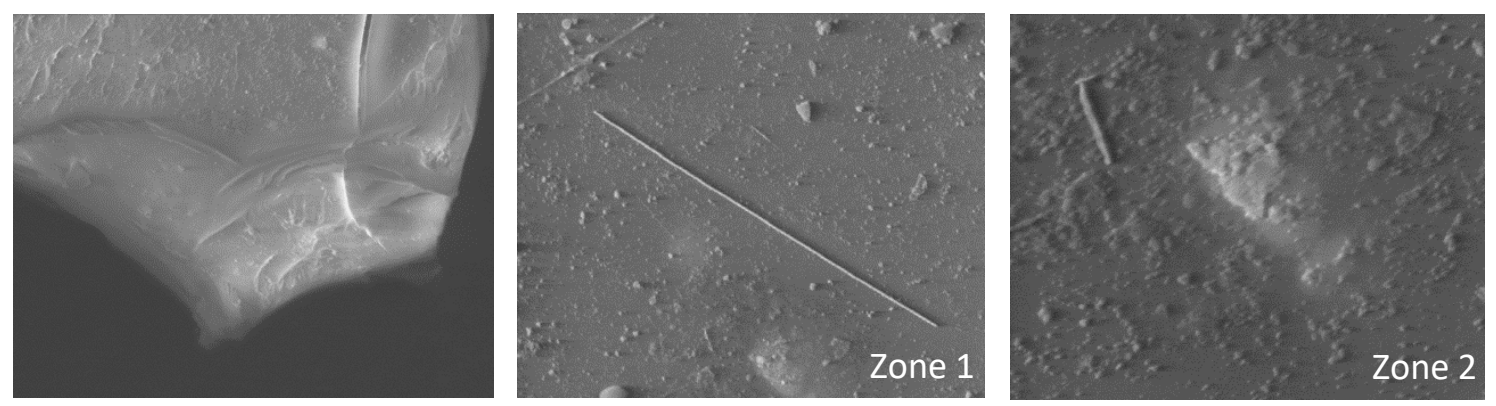

Fig. 11. ESEM observationsBentonite-P4VP 3\% (Zone 1, scale bare $=10 \mu \mathrm{m}),($ Zone 2, scale bare $=10 \mu \mathrm{m})$

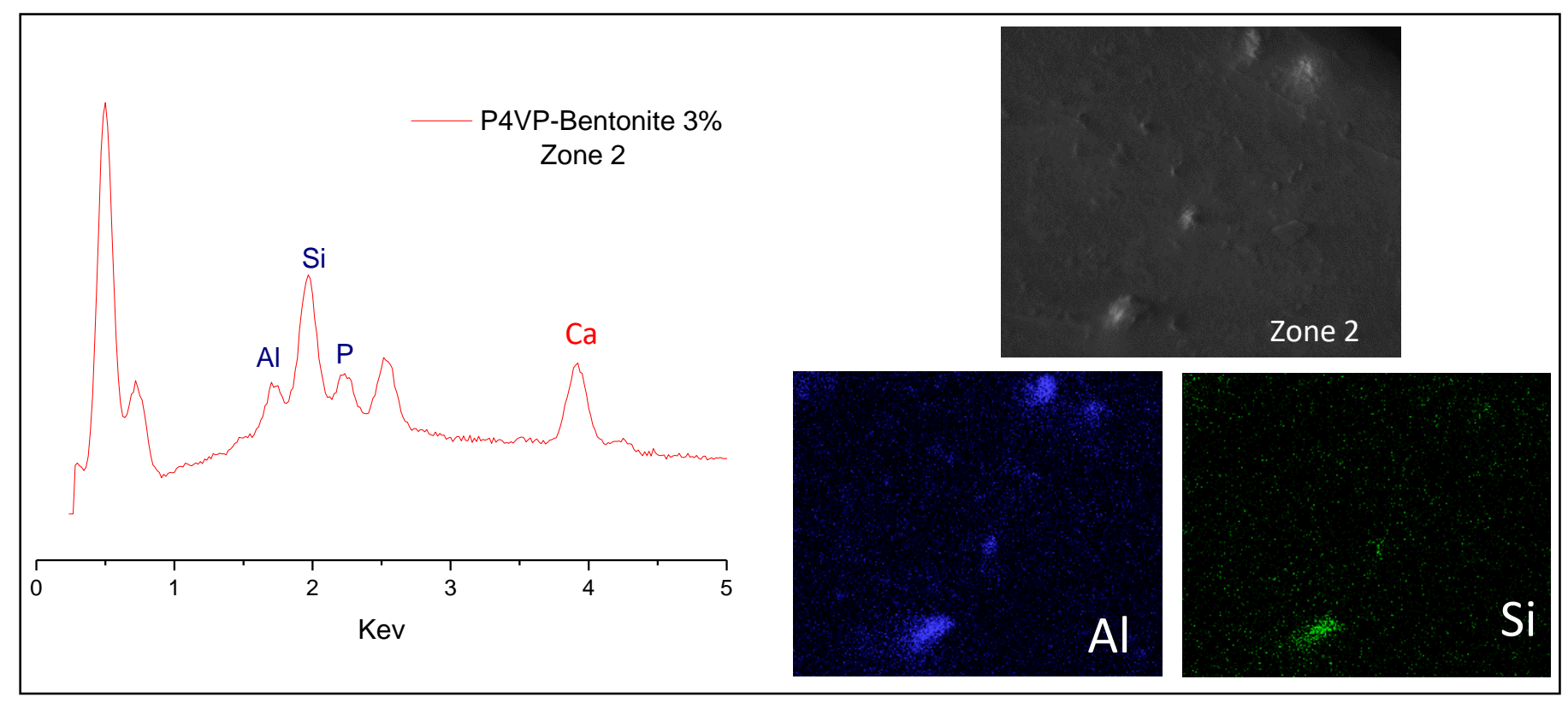

Fig. 12. ESEM observations (scale bare $=10 \mu \mathrm{m}$ ), EDX spectrum and cartography of P4VP-BC $3 \%$ composite Material (Zone 2) 

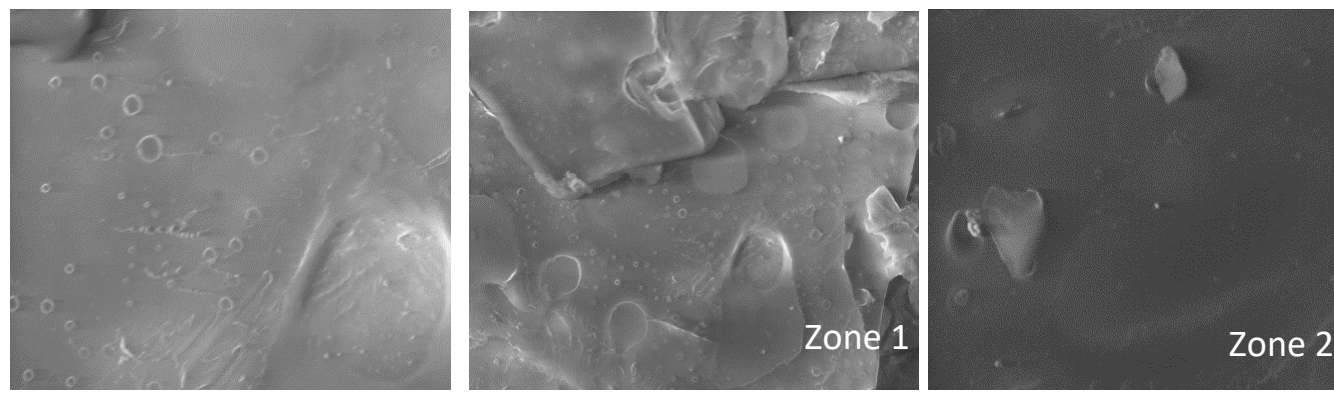

Fig. 13. ESEM observations P4VP-MC 3\% (Zone 1, scale bare = $10 \mu \mathrm{m})$, (Zone 2, scale bare = $10 \mu \mathrm{m})$

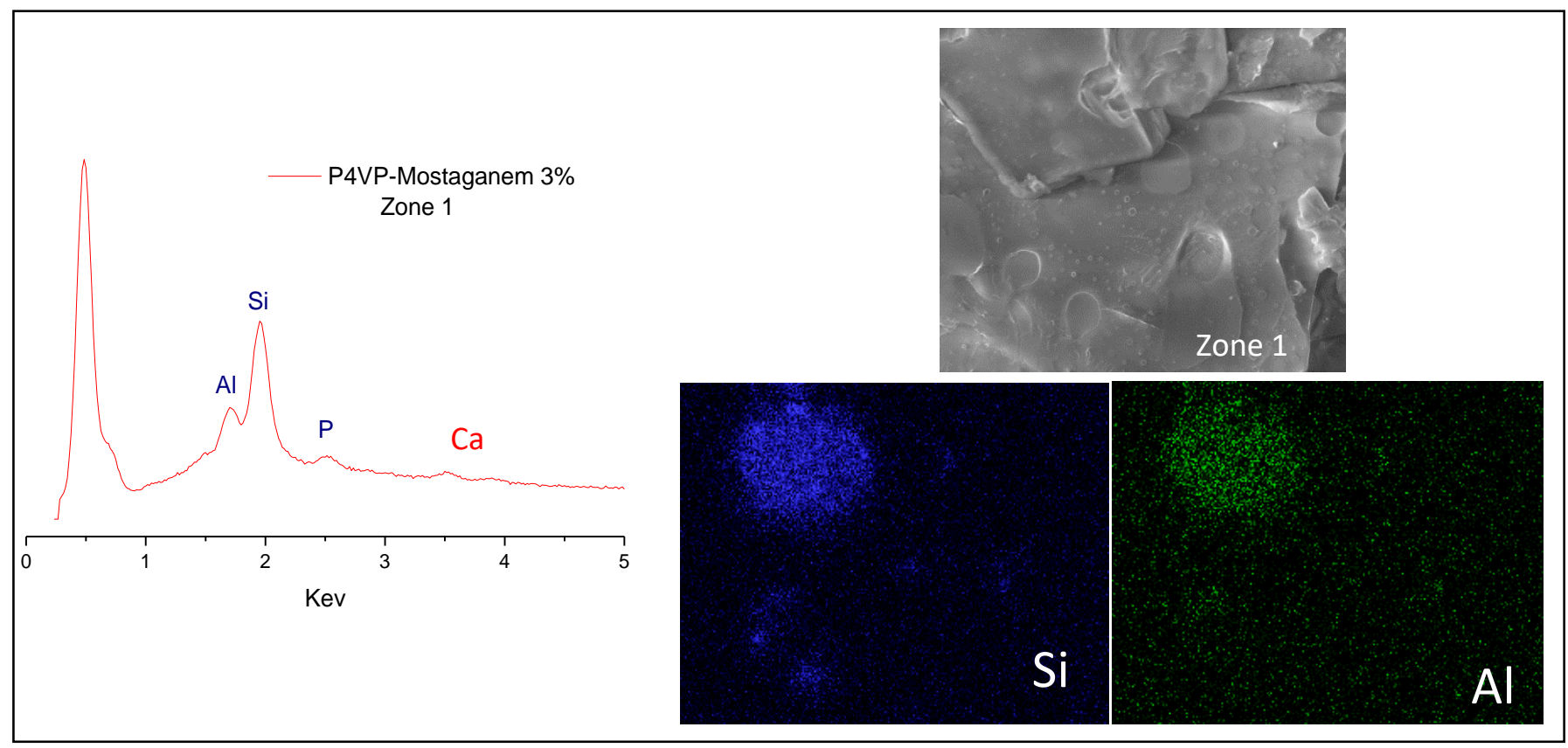

Fig. 14. ESEM observations (scale bare $=10 \mu \mathrm{m}$ ), EDX spectrum and cartography of P4VP-MC $3 \%$ composite Material (Zone 1)

\section{CONCLUSIONS}

This paper describes the In-situ polymerization of 4-vinylpyrdine monomer with two different Algerian modified clays (Maghnia and Mostaganem), noted (BC) and (MC) respectively. Different clays percentages ( $1 \mathrm{wt} \%, 3 \mathrm{wt} \%$ and $5 \mathrm{wt} \%)$ were used. The composites were characterized using Thermogravimetric Analysis (TGA), Differential Scanning Calorimetry (DSC), Fourier transform infrared analysis (IRTF), Scanning Electron Microscopy coupled with Energy dispersive X-Ray Spectroscopy (SEM-EDX) and ${ }^{1} \mathrm{H}-\mathrm{NMR}$ spectroscopy.

- TGA shows a slight improvement in thermal stability of P4VP, this improvement is much more important for composite materials-based formulation with Mostaganem clay.

- DSC shows the glass transition temperatures of the composite materials (at the middle point) decrease if compared with the Tg of the P4VP under the same conditions. This diminution of the $\mathrm{Tg}$ is attributed to the plasticization phenomenon.

- The SEM-EDX results of the raw clays show that Aluminum and silica are present with the largest percentages; these observations confirm the IRTF results. 
- The polymer was not sandwiched between the layers of clay and we have rather an encapsulation phenomenon. We have completely covered the clay particles by the polymer.

\section{REFERENCES}

1. Li, N., He, B., Xu, S., Yuan, J., Miao, J., Niu, L., Song, J.: In site formation and growth of Prussian blue nanoparticles anchored to multiwalled carbon nanotubes with poly (4vinylpyridine) linker by layer-by-layer assembly. Materials Chemistry and Physics, 133(2-3) (2012) 726-734.

2. Ozay, O., Akcali, A., Otkun, M. T., Silan, C., Aktas, N., Sahiner, N.: P (4-VP) based nanoparticles and composites with dual action as antimicrobial materials. Colloids and Surfaces B: Biointerfaces, 79(2) (2010) 460-466.

3. Mansri, A., Dergal, F., Billon, L.: Formulation and Characterization of New pH Dependent [Alizarin-poly(4-vinylpyridine)-mica] Pigments. Macromolecular Symposia, 354 (1) (2015) 131 144

4. Belhocine, M., Haouzi, A., Bassou, G., Phou, T., Maurin, D., Bantignies, J. L., Henn, F.: Isosteric heat of water adsorption and desorption in homoionic alkaline-earth montmorillonites. Chemical Physics, 501(2018) 26-34.

5. Belhocine, M., Haouzi, A., Ammari, A., Chaker, Y., Bassou, G.: On the effect of Benzethonium intercalation process: Structural and dielectric properties of exchanged montmorillonite. Colloids and Surfaces A: Physicochemical and Engineering Aspects, 577 (2019) 224-230.

6. Sridhar, S.P., John, J., Holmqvist, P., Olsson, U., Chandran, S. Joseph, B.: Adsorption of Anionic Dyes Using a Poly (styrene-block-4-vinylpyridine) Block Copolymer Organogel. Langmuir, 37(13) (2021) 3996-4006.

7. Sun, L., Jukka, T., Tanskanen, J., Hirvi, T., Seppo, K., Schatz, T., Tapani, A.: Molecular dynamics study of montmorillonite crystalline swelling: Roles of interlayer cation species and water content. Chemical Physics, 455 (2015) 23-31.

8. Qureshi, D., Behera, K.P., Mohanty, D., Mahapatra, S.K., Verma, S., Sukyai, P., Banerjee, I., Pal, S.K., Mohanty, B., Kim, D. Pal, K.: Synthesis of novel poly (vinyl alcohol)/tamarind gum/bentonite-based composite films for drug delivery applications. Colloids and Surfaces A: Physicochemical and Engineering Aspects, 613, (2021) 126043.

9. Abukhadra, M. R., Adlii, A., Bakry, B. M.: Green fabrication of bentonite/chitosan@ cobalt oxide composite (BE/CH@ $\mathrm{Co}$ ) of enhanced adsorption and advanced oxidation removal of Congo red dye and $\mathrm{Cr}$ (VI) from water. International Journal of Biological Macromolecules, 126 (2019) 402-413.

10. Bouras, B., Hocine, T., Benabadji, K. I., Benhabib, K., Mansri, A.: Optimizing the coagulation/flocculation process for bentonite suspension with poly (acrylamide-co-(N-methyl-4vinylpyridinium tosylate. Turkish Journal of Chemistry, 42(3) (2018) 748-758.

11. Koosha, M., Hamedi, S.: Intelligent Chitosan/PVA nanocomposite films containing black carrot anthocyanin and bentonite nanoclays with improved mechanical, thermal and antibacterial properties. Progress in Organic Coatings, 127 (2019) 338-347.

12. Dergal, F., Mansri, A., Billon, L.: Characterization by Tga and Uv-visible of New Pigment Materials Containing Mica, P4VP and D\&C Red 6 Dye. Chemical Engineering, 32 (2013) 21312136. 
13. Denis, L., Bizot, H., Colonna, P.: Antiplasticization in starch-glycerol films. Journal of Applied Polymer Science, 63.8 (1997) 1047-1053.

14. Zhiqiang, L.: Edible films and coatings from starches. Innovations in food packaging. Academic Press, (2005) 318-337.

15. Bacquet, M., Martel, B., Morcellet, M., Benabadji, K.I., Medjahed, K., Mansri, A., Meniai, A.H., Lehocine, M.B.: Adsorption of poly (4-vinylpyridine) onto bentonites. Materials Letters, 58(3-4) (2004) 455-459.

16. Bouktab, S., Saidat, B., Belhocine, M., Ammari, A., Dergal, F.: Structural and dielectric properties of poly (2-ethyl-2-oxazoline)/montmorillonite nanocomposite. Journal of Materials Science: Materials in Electronics, 32, 10 (2021) 13871-13881.

17. Mansri, A., Belkaid, S.: New hydrophobic hybrid inorganic and organic particles based on poly (n-hexadecyl-4-vinylpyridinium bromide) adsorption on micron-sized bentonite. Desalination and Water Treatment, 54.2 (2015) 405-411.

18. Mansri, A., Dergal, F.: Stability of hybrid inorganic-organic particles based on Poly (4Vinylpyridine) adsorption on micron-sized mica platelets. Journal of Material and Environmental Science, 4 (2012) 257-262.

19. Lerari, D., Peeterbroeck, S., Benali, S., Benaboura, A., Dubois, P.: Combining atom transfer radical polymerization and melt compounding for producing PMMA/clay nanocomposites. Journal of Applied Polymer Science, 121.3 (2011) 1355-1364.

20. He, F.A., Zhang, L.M., Jiang, H.L., Chen, L.S., Wu, Q., Wang, H.H.: A new strategy to prepare polyethylene nanocomposites by using a late-transition-metal catalyst supported on AlEt3activated organoclay. Composites Science and Technology, 67.7-8 (2007) 1727-1733.

21. He, F.A., Zhang, L.M.: New polyethylene nanocomposites prepared by in-situ polymerization method using nickel a-diimine catalyst supported on organo-modified $\mathrm{ZnAl}$ layered double hydroxide." Composites Science and Technology, 67.15-16 (2007) 3226-3232.

22. Cui, L., Tarte, N.H., Woo, S.I.: Synthesis and properties of poly (methyl methacrylate)/clay nanocomposites prepared via in situ polymerization with $\mathrm{Ni}$ (acac) 2 catalyst. Journal of Applied Polymer Science, 110.2 (2008) 784-790.

23. Claret, P.A., Williams, G.H.: Homolytic mechanisms of aromatic rearrangements. Part II. Thermal rearrangements of 1-alkylpyridinium salts (the Ladenburg rearrangement). Journal of the Chemical Society C, Organic 1 (1969) 146-151.

24. Pollock, H.M., Hammiche, A.: Micro-thermal analysis: techniques and applications. Journal of Physics D: Applied Physics, 34(9) (2001) R23.

25. Zhang, P., Cui, Y., Anderson, C.F., Zhang, C., Li, Y., Wang, R., Cui, H.: Peptide-based nanoprobes for molecular imaging and disease diagnostics. Chemical Society Reviews, 47.10 (2018) 3490-3529. 